\section{Internet information-seeking in mental health}

\author{
Population survey
}

JOHN POWELL and AILEEN CLARKE

\begin{abstract}
Background A major use of the internet is for health information-seeking.

There has been little research into its use in relation to mental health.
\end{abstract}

\begin{abstract}
Aims To investigate the prevalence of internet use for mental health informationseeking and its relative importance as a mental health information source.
\end{abstract}

Method General population survey.

Questions covered internet use, past

psychiatric history and the 12-item

General Health Questionnaire.

Results Eighteen per cent of all internet users had used the internet for information related to mental health. The prevalence was higher among those with a past history of mental health problems and those with current psychological distress. Only $12 \%$ of respondents selected the internet as one of the three most accurate sources of information, compared with $24 \%$ who responded that it was one of the three sources they would use.

Conclusions The internet has a significant role in mental health information-seeking. The internet is used more than it is trusted.

Declaration of interest None. Funding detailed in Acknowledgement.
The internet is increasingly used as a source of information on health issues (Powell \& Clarke, 2002; Baker et al, 2003). Previous work on the internet and mental health has examined the use of internet communities (Powell et al, 2003), developed and evaluated online interventions such as internet-based therapy (Christensen et al, 2004; Griffiths et al, 2004; Andersson et $a l, 2005)$ and assessed the quality of information on mental health websites (Griffiths \& Christensen, 2000). There has been surprisingly little work measuring internet use to find mental health information; in particular, no previous study has investigated the prevalence of mental healthrelated internet use among the general population, and among people with mental health problems in the community. We therefore undertook a questionnaire survey of a representative sample of the population regarding their use of the internet for information related to mental health issues. Cross-sectional surveys are useful in quantifying the views of a large number of people in a relatively cheap and timely manner. Such surveys have been used successfully in previous research into informationseeking (Case, 2002).

\section{METHOD}

\section{Survey method}

A computer-generated random sample of individuals aged 18 years or over was selected from the database of Oxfordshire general practice patients. Ethical approval was obtained from the Oxford Psychiatric Research Ethics Committee and the host institution ethics committee, and patients' general practitioners were notified. A self-completion postal questionnaire was designed based on the results of a literature review and a qualitative interview study of 36 individuals concerning mental health information needs and use of the internet. Several questions investigated internet use, both in general and with respect to mental health issues. To investigate the relative frequency of use of the internet and its trustworthiness, respondents identified the three sources of mental health information they would be most likely to use, and the three sources that they regarded as the most accurate. This determined how many people listed the internet as one of their top three choices. The item responses for these lists were based on the interview results and literature review, and were refined during pre-testing. We avoided item response bias by reversing the item order in $50 \%$ of the surveys.

The survey also included demographic questions, a question on previous psychiatric history and the 12-item General Health Questionnaire (GHQ-12; Goldberg, 1972). This is a validated self-completion instrument to assess current mental health status, chosen for its brevity and validity. The layout and appearance of the questionnaire were informed by best practice in questionnaire design (McColl et al, 2001). It was brief, to encourage a high response rate (Edwards et al, 2002). Survey pretesting and piloting were undertaken with purposive samples of the general population.

To detect a $25 \%$ difference in use of the internet for health information between those who did and those who did not have current experience of mental health problems, with $80 \%$ power and $5 \%$ significance, the survey sample required 1800 individuals (assuming that there is a $50 \%$ response rate, $45 \%$ use the internet, $60 \%$ of these have used it for health information and $25 \%$ have some current experience of mental health problems). It was therefore mailed to 1800 potential respondents. Two duplicate mailings and one postcard reminder were sent following the initial mailing, and respondents could opt to be entered in a prize draw.

\section{Analysis}

Data were double-entered. Responses were confidential and data for analysis were anonymised. The Statistical Package for the Social Sciences version 13.0 for Windows and StatsDirect version 2.4.5 (StatsDirect Ltd, Sale, Cheshire, UK; http:.//www.statsdirect.com) were used for data analysis. To determine health status the GHQ-12 scores of respondents were calculated using the standard GHQ scoring method (Goldberg \& Williams, 1988); a 
cut-off score of 2 or more indicated the presence of psychological distress (Goldberg, 1972). Univariate significance testing was carried out using chi-squared difference in proportions. Multivariate logistic regression explored the relationship between internet use, current mental health status (GHQ-12 score), past psychiatric history and socio-demographic variables. Except where stated, all $P$ values refer to $\chi^{2}$ comparisons of proportions.

\section{RESULTS}

\section{Response rates}

A total of 917 replies were received. After exclusion of patients who had died $(n=13)$ and surveys returned unopened as 'not known at this address' $(n=213)$, the adjusted response rate was $58.3 \%$ (917/1574). Respondents were significantly more likely to be female $(P<0.001)$, older $(P<0.001 ;$ unpaired $t$-test $)$, and to come from less deprived areas $(P<0.001$; Mann-Whitney $U$-test $)$ than non-respondents. The predominance of female respondents was more marked in younger age-groups.

\section{Sample characteristics}

The median age-group was 46-55 years for both men and women. There were $46.0 \%$ men and $54.0 \%$ women in the respondent sample. The mean GHQ-12 score was 1.8. Overall, $34.0 \%$ of respondents $(n=312)$ had some evidence of current mental health disturbance (GHQ-12 scores of 2 or more) and $20.1 \%$ of respondents $(n=184)$ had mental health disturbance rated as high or severe (GHQ-12 scores of 4 or greater). Of the sample, $18.2 \%$ had a self-reported history of significant mental health problems (166 out of 910 who answered this question), defined as a mental health issue or problem that had led to a consultation with a doctor or other health professional. There was a gender difference, with $15.7 \%$ of men (65/415) and $20.9 \%$ of women (101/484) reporting such history $(P=0.039)$.

\section{Internet use}

Of the total sample, $58.8 \%$ reported ever having used the internet (539/917). There was no difference by gender, with $59.9 \%$ men (249/416) and $58.2 \%$ women (284/488) having used the internet $(P=0.59)$. There was a large and significant difference by age, with $84.5 \%$ of respondents aged 45 years and under (299/354) reporting ever having used the internet $v$. $42.9 \%(240 / 560)$ of those aged 46 years and over $(P<0.001)$. There was also a large and significant difference by level of educational attainment, with $37.9 \%$ (153/404) of those who did not have qualifications at A-level standard or above having used the internet, compared with $85.0 \%$ $(335 / 394)$ of those who had this qualification or above $(P<0.001)$. Of the whole sample, $37.4 \%$ (343/917) had used the internet for general health information ('finding out about any aspect of health or healthcare'). This represented $63.6 \%$ of those who had ever used the internet. There was no relationship between general internet use or health-related internet use and either current mental health status (GHQ-12 score) or having a previous episode of mental illness, once the effects of age and educational attainment were controlled for using logistic regression. For all regression analyses the effects of GHQ-12 caseness and of past psychiatric history were examined separately, owing to the lack of independence of these variables.

\section{Use of the internet to find out about a mental health issue}

Of the whole sample, $10.6 \%$ (97/917) had used the internet to find out about mental health, representing $18.0 \%$ (97/539) of all people who had ever used the internet. The equivalent figures were $15.1 \%$ for respondents with GHQ-12 scores of 2 or more $(22.8 \%$ of those who had internet access) and $20.5 \%$ for respondents with a past history of mental health problems (31.5\% of those who had internet access). Differences by age and educational level disappeared after allowing for differential access to the internet. Differences by past psychiatric history and GHQ-12 status remained statistically significant after allowing for internet access once the effects of age, gender and educational level were controlled for (Table 1). This analysis showed that internet users with current experience of mental health distress were more likely to have used the internet to find information about a mental health issue than those without current mental health distress $(\mathrm{OR}=1.82,95 \%$ CI $1.14-2.89$, $P=0.012$ ) and those with a past history of a serious mental health problem were more likely to have used the internet for this purpose than those with no such history $(\mathrm{OR}=2.83$, 95\% CI 1.71-4.68, $P<0.001)$.

Nine of the respondents had used the internet to chat (using live interaction in a chatroom or via instant messenger) with someone else about mental health issues $(1.0 \%$ of the whole sample, $1.7 \%$ of internet users). These were four men and five women with a wide spread of age-group (18-75 years) and educational attainment (O-levels to degree). All nine had current mental health distress (GHQ-12 score of 2 or above) and five had experienced a serious mental health problem in the past.

\section{Relative importance of the internet as a source of mental health information}

Respondents were asked to select three sources they believed provided the most accurate information on mental health issues. Table 2 shows that $12.1 \%$ selected the internet as one of the top three most accurate sources of information on mental health issues. For the whole population and for those with and without current mental health problems, the results clearly demonstrate the trust put in health professionals, with mental health workers and general practitioners being rated the most accurate sources. There was no major difference by GHQ-12 caseness $\left(\chi^{2}=11.74\right.$, d.f. $\left.=12, P=0.47\right)$. Third place was taken by leaflets produced by the National Health Service (NHS) or by voluntary organisations and charities. Fourth ranking was 'someone else with the same mental health problems', and this received relatively more votes from people with mental health problems. The internet was ranked eighth overall, and sixth by people with mental health problems, although the scoring between the fifthand eighth-ranked sources was very close. There was a gender difference $\left(\chi^{2}=31.76\right.$, d.f. $=12, \quad P<0.01$ ), explained by mental health professionals being ranked ahead of general practitioners by women, whereas men ranked general practitioners slightly ahead of mental health professionals.

Respondents were also asked to indicate which three sources of information they would be most likely to use if they were seeking information on a personal mental health issue. Table 3 shows that $24 \%$ of both the general population and those with current mental health distress indicated that the internet was one of the three sources they would use, suggesting 
Table I Use of the internet for information on health issues and on mental health issues: logistic regression investigating explanatory variables among internet users $(n=539)$

\begin{tabular}{|c|c|c|c|c|}
\hline & \multicolumn{2}{|c|}{$\begin{array}{l}\text { Use of internet for } \\
\text { health information }\end{array}$} & \multicolumn{2}{|c|}{$\begin{array}{l}\text { Use of internet for mental health } \\
\text { information }\end{array}$} \\
\hline & $\begin{array}{l}\text { Odds ratio } \\
(95 \% \mathrm{Cl})\end{array}$ & $P$ & $\begin{array}{l}\text { Odds ratio } \\
(95 \% \mathrm{Cl})\end{array}$ & $P$ \\
\hline \multicolumn{5}{|c|}{ Analysis with variables $G H Q-12$ score, age, gender and educational level } \\
\hline Age 45 years or under & I.II (0.75-I.65) & 0.59 & $0.94(0.58-1.53)$ & 0.81 \\
\hline Male & $0.82(0.56-1.20)$ & 0.31 & $0.77(0.48-1.24)$ & 0.28 \\
\hline Educated to A-level or above & $1.57(1.05-2.34)$ & 0.03 & I.II (0.67-I.85) & 0.68 \\
\hline GHQ-12 score $\geqslant 2$ & $\mathrm{I} .03(0.70-\mathrm{I} .52)$ & 0.87 & $1.82(1.14-2.89)$ & 0.01 \\
\hline \multicolumn{5}{|c|}{ Analysis with variables past psychiatric history, age, gender and educational level } \\
\hline Aged 45 years or under & $1.14(0.78-1.68)$ & 0.52 & $\mathrm{I} .05(0.64-\mathrm{I} .7 \mathrm{I})$ & 0.86 \\
\hline Male & $0.84(0.57-I .24)$ & 0.38 & $0.83(0.51-1.36)$ & 0.46 \\
\hline Educated to A-level or above & $1.57(1.05-2.34)$ & 0.03 & I.I7 (0.70-I.94) & 0.56 \\
\hline Previous consultation for mental health problems & $1.32(0.82-2.12)$ & 0.25 & $2.83(1.7 I-4.68)$ & $<0.001$ \\
\hline
\end{tabular}

GHQ-12, 12-item General Health Questionnaire.

Table 2 Proportion of respondents identifying sources of information providing the most accurate information on mental health issues

\begin{tabular}{|c|c|c|c|}
\hline Rank & Source of information & $\begin{array}{c}\text { All respondents } \\
\qquad \begin{array}{c}(n=917) \\
\%\end{array}\end{array}$ & $\begin{array}{l}\text { Respondents scoring } \\
2 \text { or more on GHQ-12 } \\
\qquad \begin{array}{c}(n=312) \\
\%\end{array}\end{array}$ \\
\hline I & Mental health professional & 59.7 & 60.6 \\
\hline 2 & General practitioner & 53.8 & 52.9 \\
\hline 3 & $\begin{array}{l}\text { Leaflets from NHS or voluntary organisations or } \\
\text { charities }\end{array}$ & 29.8 & 29.5 \\
\hline 4 & Someone else with the same mental health problem & 15.3 & 17.9 \\
\hline 5 & Television or radio programmes & 15.0 & I5.I \\
\hline 6 & Friend or family member & 13.4 & 12.5 \\
\hline 7 & Newspaper or magazine articles & 13.1 & 12.8 \\
\hline 8 & Internet & 12.1 & I3.1 \\
\hline 9 & Charity or voluntary organisation telephone helpline & 7.6 & 9.3 \\
\hline 10 & Home medical encyclopaedia or similar books & 7.1 & 8.0 \\
\hline II & NHS Direct telephone helpline & 6.8 & 6.1 \\
\hline 12 & Other & 4.1 & 2.6 \\
\hline 13 & Alternative or complementary therapist & 3.5 & 5.1 \\
\hline
\end{tabular}

GHQ-12, 12-item General Health Questionnaire; NHS, National Health Service.

the internet is used more than it is trusted as an accurate medium. Table 3 also shows that general practitioners and mental health workers not only were considered the most accurate sources, but also were the most likely to be used. The internet was rated fourth overall and third equal by those with mental health problems: there was no major difference by GHQ-12 caseness $\left(\chi^{2}=9.72\right.$, d.f. $\left.=13, P=0.72\right)$.

\section{DISCUSSION}

The internet is playing a significant part in mental health information-seeking. It has been used as a source of mental health information by over $10 \%$ of the general population and by over $20 \%$ of those with a history of mental health problems. Eighteen per cent of those who had ever used the internet had used it for mental health information. The relative importance of the internet was demonstrated by $24 \%$ of the study population identifying it as one of the top three information sources they would use if they were to have a mental health problem. This contrasts with the $12 \%$ of the study population who regarded the internet as one of the top three sources providing the most accurate information. Other work has also found that the internet is ranked higher as a source to use than as a source to trust, and supports the primacy of health professionals as the most used and the most trusted sources of information for health problems (Pennbridge et al, 1999).

We believe that this is the first study to investigate the population prevalence of internet use for mental health information and the relative importance of the internet as a mental health information source. There has been work on internet use for general health matters, which shows similar findings to our survey with approximately $40 \%$ of internet users having accessed health information (Baker et al, 2003).

\section{Limitations of the study}

Cross-sectional sampling can only identify the views and reported behaviour of respondents at one point in time. Further work observing actual behaviour or following individuals prospectively might be helpful. The response rate was moderate despite the use of duplicate mailings, postcard reminders and entry into a prize draw. 
Non-respondents to the GHQ-12 are known to have a higher prevalence of psychiatric morbidity than respondents (Williams \& Macdonald, 1986). Because of the nature of the NHS, general practice registers in the UK are generally considered to provide adequate population samples; however, they are known to suffer from 'list inflation', whereby people who have been registered with a general practice can remain registered after dying or moving away (Carr-Hill \& Roberts, 1999). On average non-responders were 5.5 years younger, from areas with slightly higher deprivation scores, and were more likely to be male. These are known associations with population survey non-respondents (Purdon \& Nicolaas, 2003). However, it is difficult to judge what effects nonresponse bias might have had on the findings: for example, internet use is more common in younger age-groups (overrepresented among non-respondents) but also in less deprived groups (underrepresented among non-respondents). For generalisability, it is reassuring that the prevalence of general internet use is in line with the findings of other UK population surveys (Dutton et al, 2005).

\section{Implications}

Most people with minor mental health problems seek help from family and friends

JOHN POWELL, MA, MB BChir, MSc, PhD, MRCPsych, MFPHM, Health Sciences Research Institute, University of Warwick, Coventry; AlLEEN CLARKE, BA, BM BCh, MD, MSc, MRCGP, FFPHM, Public Health \& Policy Research Unit, Institute of Community Health Sciences, Barts and The London, Queen Mary's School of Medicine and Dentistry, Queen Mary, University of London, Mile End Road, London, UK

Correspondence: Dr John Powell, Health Sciences Research Institute, Medical School Building, Gibbet Hill Campus, University of Warwick, Coventry CV4 7AL, UK. Email: john. powell@warwick.ac.uk

(First received 2I September 2005, final revision 20 March 2006, accepted 2 May 2006)

rather than professionals (Oliver et al, 2005). Practitioners and policy makers must also take note of the role of the internet in help-seeking behaviour. Almost a third of internet users with a history of psychiatric disorder had used the internet to seek mental health information. A few respondents had used the internet for live chat with others about mental health issues and this is an area likely to see future expansion. As an information source the internet has advantages of privacy, anonymity and widespread accessibility at low or no cost (Cline \& Haynes, 2001). However, it appears that the public also recognises the frequently expressed concern of professionals regarding the accuracy of online information (Christensen \& Griffiths, 2000). The internet is mostly unregulated, but there are voluntary initiatives to encourage quality assessment of health information sites (Risk \&

Table 3 Proportion of respondents identifying sources of information on mental health issues that they would be most likely to use

\begin{tabular}{|c|c|c|c|}
\hline Rank & Source of information & $\begin{array}{l}\text { All respondents } \\
\qquad \begin{array}{c}(n=917) \\
\%\end{array}\end{array}$ & $\begin{array}{l}\text { Respondents scoring } \\
\begin{array}{c}2 \text { or more on GHQ-12 } \\
\left(\begin{array}{c}n=3 \mid 2) \\
\%\end{array}\right.\end{array}\end{array}$ \\
\hline I & General practitioner & 74.2 & 73.1 \\
\hline 2 & Mental health professional & 57.1 & 57.1 \\
\hline 3 & $\begin{array}{l}\text { Leaflets from NHS or voluntary organisations or } \\
\text { charities }\end{array}$ & 27.7 & 24.0 \\
\hline 4 & Internet & 23.6 & 24.0 \\
\hline 5 & Friend or family member & 18.0 & 18.3 \\
\hline 6 & Someone else with the same mental health problem & 13.0 & 13.8 \\
\hline 7 & Home medical encyclopaedia or similar books & 11.7 & 9.9 \\
\hline 8 & Charity or voluntary organisation telephone helpline & 8.8 & 9.3 \\
\hline 9 & NHS Direct telephone helpline & 7.0 & 8.0 \\
\hline 10 & Newspaper or magazine articles & 6.3 & 8.0 \\
\hline II & Alternative or complementary therapist & 5.5 & 6.4 \\
\hline 12 & Television or radio programmes & 3.5 & 3.5 \\
\hline 13 & Other & 1.3 & 0.6 \\
\hline
\end{tabular}

GHQ-12, 12-item General Health Questionnaire; NHS, National Health Service.
Dzenowagis, 2001; Griffiths \& Christensen, 2005). However, poor-quality information has always existed in various forms, and there have been only a few isolated case reports of individuals coming to harm from online information (Crocco et $a l, 2002)$. The need is for a better understanding of how individuals actually use the internet, what they do with the information they find and how internet helpseeking relates to other help-seeking behaviour. By examining the role of the internet in meeting information needs, psychiatric services and practitioners could harness the internet as a tool to educate and support patients. This is particularly important in mental health, where the internet may have a role in supporting those for whom stigma inhibits help-seeking through more traditional routes (Berger et al, 2005).

\section{ACKNOWLEDGEMENT}

J.P. was funded by the National Health Service Research and Development programme on a training fellowship in health services research.

\section{REFERENCES}

Andersson, G., Bergström, J., Holländare, F., et al (2005) Internet-based self-help for depression: randomised controlled trial. British Journal of Psychiatry, I87, 456-46I.

Baker, L., Wagner, T. H., Singer, S., et al (2003) Use of the internet and e-mail for health care information: results from a national survey. JAMA, 289, 2400-2406.

Berger, M., Wagner, T. H. \& Baker, L. C. (2005) Internet use and stigmatized illness. Social Science and Medicine, 61, 1821-1827.

Carr-Hill, R. \& Roberts, D. (1999) Population figures for capitation formulas need to be designed differently. BMJ, 318, 1145 .

Case, D. O. (2002) Looking for Information. A Survey of Research on Information Seeking, Needs, and Behaviour. San Diego: Academic Press.

Christensen, H. \& Griffiths, K. (2000) The internet and mental health literacy. Australian and New Zealand Journal of Psychiatry, 34, 975-979.

Christensen, H., Griffiths, K. M. \& Jorm, A. F. (2004) Delivering interventions for depression by using the internet: randomised controlled trial. BMJ, 328, 265 
Cline, R. J. \& Haynes, K. M. (200I) Consumer health information seeking on the internet: the state of the art. Health Education Research, 16, 67I-692.

Crocco, A. G., Villasis-Keever, M. \& Jadad, A. R.

(2002) Analysis of cases of harm associated with use of health information on the internet. JAMA, 287, 2869-287|

Dutton, W. H., Di Gennaro, C. \& Millwood

Hargrave, A. (2005) The Internet in Britain: The Oxford Internet Survey (OxIS). Oxford: Oxford Internet Institute.

Edwards, P., Roberts, l., Clarke, M., et al (2002)

Increasing response rates to postal questionnaires: systematic review. BMJ, 324, II83.

Goldberg, D. P. (1972) The Detection of Psychiatric Illness by Questionnaire. London: Oxford University Press.

Goldberg, D. P. \& Williams, P. (1988) A User's Guide to the General Health Questionnaire. Windsor: nferNelson.

Griffiths, K. M. \& Christensen, H. (2000) Quality of web based in formation on treatment of depression: cross sectional survey. BMI, 32I, I5II-1515.
Griffiths, K. M. \& Christensen, H. (2005) Website quality indicators for consumers. Journal of Medical Internet Research, 7, e55.

Griffiths, K. M., Christensen, H., Jorm, A. F., et al (2004) Effect of web-based depression literacy and cognitive-behavioural therapy interventions on stigmatising attitudes to depression: randomised controlled trial. British Journal of Psychiatry, $\mathbf{1 8 5}$ 342-349.

McColl, E., Jacoby, A., Thomas, L., et al (200I) Design and use of questionnaires: review of best practice applicable to surveys of health service staff and patients. Health Technology Assessment, 5, 31

Oliver, M. I., Pearson, N., Coe, N., et al (2005) Help seeking behaviour in men and women with common mental health problems: cross-sectional study. British Journal of Psychiatry, 186, 297-30I.

Pennbridge, J., Moya, R. \& Rodrigues, L. (1999) Questionnaire survey of California consumers' use and rating of sources of health care information including the internet. Western Journal of Medicine, I7I, 302-305.
Powell, J. \& Clarke, A. (2002) The WWW of the World Wide Web: who, what, and why? Journal of Medical Internet Research, 4, e4.

Powell, J., McCarthy, N. \& Eysenbach, G. (2003) Cross-sectional survey of users of internet depression communities. BMC Psychiatry, 3, 19.

Purdon, S. \& Nicolaas, G. (2003) Trends in Non-response on Social Surveys - The Survey Context for the One Number Census. London: National Centre for Social Research.

Risk, A. \& Dzenowagis, J. (200I) Review of internet health information quality initiatives. Journal of Medical Internet Research, 3, e28.

Williams, P. \& Macdonald, A. (1986) The effect of non-response bias on the results of two-stage screening surveys of psychiatric disorder. Social Psychiatry, 21, 182-186. 